\title{
Clinical Features of Mental Disorders among Pregnant Women
}

\author{
${ }^{1}$ Victor A. Ruzhenkov, ${ }^{2}$ Ruslan T. Kuliev, ${ }^{3}$ Sergey P. Pakhomov, ${ }^{4}$ Irina N. Verzilina, ${ }^{5}$ Victoria V. \\ Ruzhenkova, ${ }^{6}$ Inna S. Lukyantseva \\ 1, 2, 3, 4, 5, 6 Belgorod State University, Pobeda Street 85, Belgorod, 308000 Russia. \\ *Email: ruzhenkov@bsu.edu.ru
}

\section{Received: 21st October 2017 Accepted: 16th November 2017, Published: 31st December 2017}

\begin{abstract}
A sample of 450 women with a normal pregnancy was examined using the clinical, psychopathological and psychometrical methods. Clinically outlined mental disorders with a predominance of neurotic, stress-related and somatoform disorders were found in $26.9 \%$ of cases. In $8.4 \%$ of cases pre-morbid (prenosological) mental disorders were detected. Psychometric examination revealed that $11.7 \%$ of pregnant women without clinical signs of psychiatric disorders had mild symptoms of anxiety, depression and asthenia. In most cases (79.3\%), mental disorders were formed long before pregnancy, flowed in a mild form, and the majority (94.2\%) of women did not seek help from a psychiatrist. The fifth $(20.7 \%)$ part of diagnosed mental disorders, formed during pregnancy, were perceived by women as a natural "aspect of pregnancy". Gestational, individual-personal and socialenvironmental factors played a significant role in the genesis of the pre-morbid mental disorders and conditions with high risk of disadaptation. Conducting sessions of relaxation training aimed at reducing anxiety and normalizing moods had a beneficial effect on the mental status of pregnant women and the course of pregnancy.
\end{abstract}

Keywords: Pregnancy, Mental Disorders, Prenosological Mental Disorders, Psychological Features, Mental Disadaptation.

\section{Introduction}

Pregnancy, taking place without complications, is registered from $22.6 \%$ [1] to $36.2 \%$ [2] among women in Russia. Body reorganization during pregnancy can lead to both its pathology and cause disorders of the mental sphere [3]. The onset of pregnancy contributes to the aggravation of premorbid characteristics, leads to acute types of adaptation to pregnancy, anxiety and insecurity [4], exacerbating existing emotional disorders [5]. The states of anxiety of various levels are observed in $40 \%$ of women with a normal pregnancy $[6,7]$. Almost $70 \%$ of pregnant women show individual symptoms of depression, and the incidence of perinatal depressions amounts to $10-20 \%[8,9,10]$. The risk factors for the occurrence of mental disorders in pregnant women are emotional lability, irritability, spontaneous aggression and pregnancy overvaluation [11]. The pregnant women with mental disorders have a high percentage of cesarean section and high incidences of neonatal pathology are noted [12]. Anxiety disorders significantly affect the course of pregnancy and perinatal outcomes [5, 7].

There is another point of view, suggesting that pregnancy is essentially not associated with an increased risk of mental disorders [13, 14], although it is allowed the risk of depression in young, unmarried women with stressful life events and complicated pregnancy. Thus, there is conflicting information about the prevalence and clinical structure of mental disorders during pregnancy in the literature.

Due to the widespread prevalence, screening of mental disorders in pregnant women and providing them with primary health care is topical [15]. It has been proven that active treatment of pregnant women with mental disorders helps prevent the aggravation or relapse of mental disorders during pregnancy and in the postpartum period [16].

\section{Aim}

In this regard, the aim of the study was to study the features of clinical manifestation of mental disorders in women with a physiologically occurring pregnancy to develop recommendations for medical and psychological support.

\section{Materials and Methods}

We examined 450 women aged from 17 to 38 $(25.6 \pm 4.4)$ years old with a physiologically occurring pregnancy at the end of the second and third trimester to identify whether they had some mental disorders.

The criteria for including pregnant women in the study were as follows: absence of gestosis and exacerbation of somatic disease, absence of fetal pathology. The exclusion criteria were as follows: presence of gestosis, exacerbation of somatic disease, presence of fetal development pathology.

The main research methods were as follows: clinical-psychopathological, clinical-dynamic, psychometric: a method for determining the character accentuations by Leonhard-Shmishek, the self-esteem test of interpersonal relations by Leary, the hospital anxiety and depression scale (HADS), the scale of asthenic state by L.D. Maykov and T.G. Chertov and statistical method (descriptive statistics, factor analysis by the principal components method with varimax factor rotation). 


\section{Results and Discussion}

Clinical-psychopathological analysis revealed a variety of disorders of the mental sphere in $26.9 \%$ of cases (Table 1). In addition, pre-morbid (prenosological) psychiatric disorders were found in $8.4 \%$ of cases and the states of increased maladaptation risk - in $11.8 \%$.

Table 1: The Clinical Structure of Mental Disorders in Women with Physiological Pregnancy

\begin{tabular}{|c|c|l|r|r|}
\hline$\#$ & $\begin{array}{c}\text { ICD-10 } \\
\text { codes }\end{array}$ & \multicolumn{1}{|c|}{ Disorders } & n & \% \\
\hline 1 & $\mathbf{0 0}$ & Mentally healthy & $\mathbf{2 3 8}$ & $\mathbf{5 2 . 9}$ \\
\cline { 3 - 5 } & & Prenosological states & 38 & 8.4 \\
\cline { 2 - 5 } & & High risk of maladaptation & 53 & 11.8 \\
\hline 2 & F0 & Organic, including symptomatic, mental disorders & 11 & 2.4 \\
\hline 3 & F1 & Mental and behavioural disorders due to psychoactive substance use & 9 & 2.0 \\
\hline 4 & F2 & Schizophrenia, schizotypal and delusional disorders & 1.1 \\
\hline 5 & F3 & Mood [affective] disorders & 63 & 12.7 \\
\hline 6 & F4 & Neurotic, stress-related and somatoform disorders & 13 & 2.9 \\
\hline 7 & F6 & Disorders of adult personality and behaviour & 8 & 1.8 \\
\hline 8 & F7 & Mental retardation & 450 & 100.0 \\
\hline
\end{tabular}

More often than not, $14.0 \%$ of mental disorders in pregnant women were represented by the neurotic (associated with stress) and somatoform disorders. The second place was taken by the personality disorders $(2.9 \%)$, the third place - by the affective mood disorders $(2.7 \%)$, and the organic, including symptomatic mental disorders, were found less commonly - in $2.4 \%$ of cases.

In most cases, $79.3 \%$ of psychiatric disorders were formed long before pregnancy, and the vast majority (94.2\%) of patients did not seek help from a psychiatrist. The fifth part - 20.7\% - of mental disorders was formed during pregnancy and was perceived by women as its natural manifestation.

The clinical picture of the preclinical mental disorders was determined by the syndromic incompleteness, insignificant expression of vegetative symptoms. In $44.7 \%$ of cases, the clinical picture was exhausted by a set of single, unrelated syndrome asthenic, affective and vegetative symptoms that arose in connection with the subjective experiences of pregnant women about pregnancy (its course, forthcoming birth, caring for a small child, etc.). We qualified this condition as a non-pathological adaptive asthenicvegetative reaction. In the remaining $55.3 \%$ of cases, apart from individual asthenic, affective and vegetative ones, there were isolated obsessive, hysterical and hypochondriacal symptoms, not interconnected in a single clinically outlined syndrome. We qualified this condition within the framework of non-pathological adaptive asthenoneurotic reaction with sharpening the premorbid personality traits.

The study of personal characteristics of pregnant women, creating a predisposition for the formation of donosological mental disorders, revealed 3 significant factors (Table 2), explaining $65.2 \%$ of the variance.

Table 2: Personal Risk Factors for Prenosological Mental Disorders

\begin{tabular}{|l|l|l|c|}
\hline$\#$ & \multicolumn{1}{|c|}{ Factors } & \multicolumn{1}{c|}{ Components } & \% of dispersion \\
\hline 1 & Insularity & $\begin{array}{l}\text { Cyclothymic (0.769) } \\
\text { Demonstrativeness (-0.855) }\end{array}$ & 27.8 \\
\hline 2 & Anxiety & Anxiety (0.802) & 22.2 \\
\hline 3 & Instability & $\begin{array}{l}\text { Dysthymia (0.772) } \\
\text { Pedantry (-0.783) }\end{array}$ & 15.2 \\
\hline
\end{tabular}

Factor analysis made it possible to identify 2 significant factors (Table 3), concerning the features of interpersonal interaction of pregnant women, which were a risk factor for the formation of donosological mental disorders $(75.7 \%$ of the variance). 
Table 3: Communicative Risk Factors for Prenosological Mental Disorders

\begin{tabular}{|l|l|l|c|}
\hline$\#$ & \multicolumn{1}{|c|}{ Factors } & \multicolumn{1}{c|}{ Components } & \% of dispersion \\
\hline 1 & The contradictory nature of the & Authoritarianism $(0.919)$ & 51.8 \\
& interaction & Selfishness $(0.809)$ & \\
& & Dependence $(0.712)$ & \\
& & Friendliness $(0.888)$ & \\
\hline 2 & Suspicion & Altruistic $(0.904)$ & \\
& & Aggressiveness $(0.833)$ & 23.9 \\
& & Suspicion $(0.864)$ & \\
& & Subordination $(0,857)$ & \\
\hline
\end{tabular}

In the conditions of increased disadaptation risk, despite the harmonious family relationships in most women before the onset of pregnancy, the tensions with the spouse arose later (from the second-third trimester). This was due to the change in the previously developed stereotype of life, and the resulting asthenic syndrome, which prevented functioning at the same level. The latter also caused a tense relationship in the family. The states of maladaptation arose at the simultaneous negative impact of the microsocial environment (strained family relations, lack of or insufficient support), individual-personal characteristics (inconsistency, inclination to conflict and leadership) and physiological factors (pregnancy). Asthenia, subclinical anxiety and depression also created the risk of conditions that threatened maladaptation. These conditions were a kind of predisposition of donosological mental disorders and required the provision of psychotherapeutic assistance.

The study of changes in the character of interpersonal relationships as a result of pregnancy with the help of Liri's test "I'm before Pregnancy" and "I'm in Pregnancy" showed a decrease in the level of authoritarianism, selfishness, aggressiveness, subordination and dependence. Nevertheless, the factor analysis of interpersonal relationships revealed 2 significant factors that created a high risk of maladaptation in pregnant women $-82.1 \%$ of the variance (Table 4 ).

Table 4: Communicative Risk Factors for Prenosological Mental Disorders

\begin{tabular}{|l|l|l|c|}
\hline \multicolumn{1}{|c|}{$\#$} & \multicolumn{1}{|c|}{ Factors } & \multicolumn{1}{|c|}{ Components } & \% of dispersion \\
\hline 1 & Altruism & Subordination (0.862) & 48.4 \\
& & Dependence $(0.868)$ & \\
& & Friendliness $(0.941)$ & \\
\hline 2 & Altruistic (0.948) & 33.7 \\
& Selfishness & Selfishness (0.903) & \\
& & Aggressiveness (0.901) & \\
& & Suspicion (0,839) & \\
\hline
\end{tabular}

The personal factors that create the risk of maladaptation states in pregnant women $(62.1 \%$ of variance $)$ included the following (Table 5).

Table 5: Personal Risk Factors for Maladaptation

\begin{tabular}{|l|l|l|c|}
\hline \multicolumn{1}{|c|}{ F } & \multicolumn{1}{|c|}{ Factors } & \multicolumn{1}{c|}{ Components } & \multicolumn{1}{c|}{$\begin{array}{c}\text { of } \\
\text { dispersion }\end{array}$} \\
\hline 1 & Dysthymia & $\begin{array}{l}\text { Dysthymia }(0,933) \\
\text { Unstability }(0,831) \\
\text { Exaltation }(0,918)\end{array}$ & 28.0 \\
\hline 2 & Hyperthymia & $\begin{array}{l}\text { Hyperthyme }(0,850) \\
\text { Pedantry }(0,724) \\
\text { Demonstrativity }(0,704)\end{array}$ & \\
\hline 3 & Lability & $\begin{array}{l}\text { Persistent }(-0,793) \\
\text { Anxiety }(-0,733)\end{array}$ & \\
\hline
\end{tabular}

Thus, there is a risk of states that threaten maladaptation with the simultaneous negative impact of the microsocial environment (strained family relationships, lack of or insufficient support), individual personality traits (nonconformity, propensity to conflict and leadership) and physiological (pregnancy) factors accompanied by asthenia, subclinical anxiety and depression. These conditions are a kind of predisposition of donosological mental disorders and require the provision of psychotherapeutic assistance.

In total, $47.1 \%$ of pregnant women surveyed to some extent needed medical and psychological assistance. $52.4 \%$ of them agreed to the proposed 
assistance. The structure of the assistance provided

is presented in Table 6 .

Table 6: Structure of Psychopharmacological and Psychotherapeutic Care

\begin{tabular}{|c|c|c|c|c|c|c|c|}
\hline \# & Disorders & PPT & $\%$ & PT & $\%$ & PPT+PT & $\%$ \\
\hline 1 & High risk of maladaptation & - & - & 23 & 41.1 & - & - \\
\hline 2 & Prenosological states & - & - & 18 & 47.4 & - & - \\
\hline 3 & $\begin{array}{l}\text { Organic, including } \\
\text { disorders (F0) }\end{array}$ & 9 & 81.8 & 9 & 81.8 & 9 & 81.8 \\
\hline 4 & $\begin{array}{l}\text { Mental and behavioural disorders due to } \\
\text { psychoactive substance use }(\mathrm{F} 1)\end{array}$ & - & - & 6 & 66.7 & - & - \\
\hline 5 & $\begin{array}{l}\text { Schizophrenia, schizotypal and delusional } \\
\text { disorders (F2) }\end{array}$ & 5 & 100.0 & - & - & - & - \\
\hline 6 & Mood [affective] disorders (F3) & 12 & 100.0 & - & - & - & - \\
\hline 7 & $\begin{array}{l}\text { Neurotic, stress-related and somatoform } \\
\text { disorders (F4) }\end{array}$ & 23 & 36.5 & 26 & 41.3 & 23 & 36.5 \\
\hline 8 & Disorders of adult personality and behaviour (F6) & 6 & 46.2 & 7 & 53.8 & 6 & 46.2 \\
\hline 9 & Mental retardation $(\mathrm{F} 7)$ & 5 & 62.5 & - & - & - & - \\
\hline & TOTAL & 60 & 28.3 & 89 & 42.0 & 38 & 17.9 \\
\hline
\end{tabular}

PPT - psycho pharmacotherapy; PT - psychotherapy; PPT+PT - psycho pharmacotherapy with psychotherapy.

Psycho pharmacotherapy was aimed at eliminating anxiety and depression. It was assigned small antipsychotics and antidepressants from the SSRI group. Psychotherapeutic help was aimed at eliminating emotional tension and harmonizing interpersonal relationships. The training program was comprehensive, developed on the basis of modern relaxation techniques, psycho-technologies of neurolinguistic programming and Ericksonian hypnosis and included the following directions:

- impact on the emotional sphere: neutralization of anxiety and depression and harmonization of interpersonal relations;

- work with the cognitive sphere: awareness of the stages of maternal dominant, changes in one's own well-being and behavior, problems in connection with the changed relationships in the family;

- impact on the behavioral sphere: communication with the child, playing problem family situations;

- impact on the bodily sphere: awareness and acceptance of bodily changes as a result of pregnancy.

We applied relaxation training, visually-kinesthetic anxiety dissociation, resource techniques.

As a result of the course, all pregnant women improved their mood and overall well-being, the anxiety significantly decreased. In all cases, the third trimester of pregnancy proceeded without complications.

\section{Conclusion}

The data presented indicate the actualization of conflicting personality traits in pregnant women during pregnancy, which is a risk factor for conflict situations and tensions with the formation of borderline mental disorders. Considering the high specific gravity of mental disorders in pregnant women with physiological pregnancy, their donosological forms, as well as the high risk of maladaptation, there is an urgent need for consulting and diagnostic work with pregnant by the psychotherapist and clinical psychologist. Conducting sessions of relaxation training aimed at reducing anxiety and normalizing moods has a beneficial effect on both the mental status of pregnant women and the course of pregnancy.

\section{References}

[1] Mikhaylin, E.S., Ivanova, L.A., Savitsky, A.G., Zhibura, L.P., Minina, A.G., 2014. Features of the course of pregnancy and childbirth in imperfectly old women in a megacity (on the example of St. Petersburg). Journal of Obstetrics and Women's Diseases, 63(3). 36-43. (In Russian).

[2] Vetushenko, S.A., Zakharova , T.G., 2014. The frequency and severity of complications of pregnancy and childbirth in women with tuberculosis of various locations in the Krasnoyarsk Territory. Journal of Obstetrics and Women's Diseases, 63(3): 58-65. (In Russian).

[3] Halbreich, U., 2005. The association between pregnancy processes, preterm delivery, low birth weight, and postpartum depressions - the need for interdisciplinary integration. Am. J. Obstet. Gynecol., 193:1312-1322.

[4] Ladyina, V.Yu., 2004. Complex model of preparation of pregnant women for childbirth in the prevention of psychosomatic dezadaptations of parturient women: $\mathrm{PhD}$ thesis in Psychology. -St. Petersburg, 2004. 25 p. (In Russian).

[5] Soares, C.N., Steiner, M., 2009. Perinatal depression: searching for specific tools for a closer look at this window. J. Clin. Psychiatry, 70(9): 1317-1318. 
[6] Avedisova, A.S., 2004. Anxious disorders. In: Alexandrovsky, Yu.A. Mental disorders in general medical practice and their treatment. Moscow: «GEOTAR-MED», 2004: 66-73. (In Russian).

[7] Gavin, N.I., Gaynes, B.N., Lohr, K.N., MeltzerBrody, S., Gartlehner, G., Swinson, T., 2005. Perinatal depression: a systematic review of prevalence and incidence. Obstet Gynecol., 106: 1071-1083.

[8] Hallberg, P., Sjoblom, V., 2005. The use of selective serotonin reuptake inhibitors during pregnancy and breast-feeding: a review and clinical aspects. J Clin Psychopharmacology, 25:59-73.

[9] Buist, A., 2006. Perinatal depression. Assessment and management. Aust Fam Physician, 35: 670-673.

[10] De Jesus Silva, M.M., Peres Rocha Carvalho Leite, E., Alves Nogueira, D., Clapis, M.J., 2016. Depression in pregnancy. Prevalence and associated factors. Invest Educ Enferm, 34(2): 342-350.

[11] Ruzhenkov, V.A., Kolosova, M.A., Ruzhenkova, V.V., 2014. Psychiatric Disorders among Women after Late Term Therapeutic Abortions (Clinical Findings and Risk Factors).
Research Journal of Pharmaceutical, Biological and Chemical Sciences, 5: 1083-1086.

[12] Bosquet, M., Egeland, B., 2000. Predicting parenting behaviors from Antisocial Practices content scale scores of the MMPI-2 administered during pregnancy. J. Pers. Assess., 74(1): 146-162. [13] Vesga-Lopez, O., Blanco, C., Keyes, K., Olfson, M., Grant, B.F., Hasin, D.S., 2008. Psychiatric Disorders in Pregnant and Postpartum Women in the United States. Arch. Gen Psychiatry, 65 (7): 805-815.

[14] Ruzhenkov, V.A., Kuliev, R.T., Ruzhenkova V.V., Boeva, A.V., 2014. Psychopharmacotherapy of mental disorders in the course of physiological pregnancy. Research Journal of Pharmaceutical, Biological and Chemical Sciences, 5: 1087-1090.

[15] Rondó, P.H.C., Ferreira, R.F., Lemos, J.O., Pereira-Freire, J.A., 2016. Mental disorders in pregnancy and 5-8 years after delivery Glob Ment Health (Camb). 23(3): e31. eCollection 2016.

[16] Suzuk, I.S., 2017. Recent status of pregnant women with mental disorders at a Japanese perinatal center. J Matern Fetal Neonatal Med., 31: $1-19$. 